\title{
Introduction
}

\section{Generative Diachronic Syntax: Word order and information structure}

\author{
Montserrat Batllori \\ Universitat de Girona. Departament de Filologia i Comunicació \\ montserrat.batllori@udg.edu
}

\section{Lluïsa Hernanz}

Centre de Lingüística Teòrica

Universitat Autònoma de Barcelona. Departament de Filologia Espanyola

luisa.hernanz@uab.cat

\section{Introduction}

In recent times, there has been an increasing concern for the interaction between information structure and syntax, and its effect in language change. ${ }^{1}$ The aim of this volume is to provide the reader with comparative research into the role of information structure in language change from a crosslinguistic perspective and to contribute to a better understanding of structural changes and their possible relation to information structure factors.

From a synchronic standpoint, information packaging is jointly conveyed by semantics, prosody and syntax. In contrast, diachronic linguistics lacks the evidence of prosodic information, but it can still rely on the relation between discourse semantics and syntax in old written texts, as well as on the comparison with synchronic data, to set light on the phenomena involved in syntactic changes driven by information structural configurations.

Concerning language change, it is generally accepted that the focus of investigation is on I-language and that language acquirers select cues that are robustly represented in main clauses of the Primary Linguistic Data of their environment so

1. Apart from specific research projects such as The role of information structure in language change (Humboldt-Universität zu Berlin / Universität Potsdam) or Information structure in Welsh and its implications for diachronic syntactic change (Leiden University Centre for Linguistics), among others, several books and monographs have been and are still being devoted to research on this topic. See, in this respect, Breul and Göbbel (2010), Ferraresi and Lühr (2010), and the latest issues in Lingua. 
as to feed into particular parameters of UG (see Fischer et al. 2000, Batllori et al. 2005, Kemenade 2007 and Roberts 2007). From this cue-based acquisition perspective, it could be the case that information structural factors might constitute triggers for syntactic changes (for example, word order change -see Westergaard 2010).

The analysis of discursive information in written texts has increased in recent years due to the contribution of the cartographic approach (from Rizzi 1997 onwards) and the studies related to the CP field within the minimalist program. These two approaches, even though apparently in conflict, are actually complementary in many respects. As Cinque and Rizzi (2008: 49) observe, «Minimalism focuses on the generating devices, and cartography focuses on the fine details of the generated structures, two research topics which can be pursued in parallel in a fully consistent manner, and along lines which can fruitfully interact».

Crucial to the cartographic approach is the claim that the $\mathrm{C}$ system should be decomposed into a more articulated sequence of functional projections. According to Rizzi (1997), the CP domain minimally consists of a specification of Force besides a specification of (non) finiteness for IP. Additionally, it may also include a Topic and a Focus field, expressing the topic-comment and focus-presupposition articulation respectively. As a consequence, the $\mathrm{CP}$ node splits into four separate projections, as represented in (1):

(1) $\left[_{\text {ForceP }} F\left[_{\text {TopicP }}\right.\right.$ Top $[$ FocusP Foc $[$ FinitenessP Fin .... ] ] ] ]

As opposed to the force-finiteness system, Topic and Focus are closely related to the information structure of the sentence. The Topic projection (TopP) is activated to host topicalized constituents, expressing old information. The Focus projection $(F o c P)$ is the locus of focalized elements, which introduce new information.

Incorporating a cartographic approach allows us to gain further insight into the interaction between information structure and particular syntactic phenomena. In earlier works, as in Fontana (1993), on the basis of the O-V-S order of Old Spanish data, Old Spanish was regarded as a V2 language, and consequently the following analysis was proposed:

(2) $\left[_{\text {SPEC IP }}\right.$ este lugar ${ }_{\mathrm{i}}\left[\left[_{\mathrm{I}}\right.\right.$ mostró $]\left[{ }_{\mathrm{V}_{\mathrm{P}}}\right.$ Dios $\left[{ }_{\mathrm{V}},\left[{ }_{\mathrm{V}}, \mathrm{t}_{\mathrm{V}} \mathrm{t}_{\mathrm{i}}\right]\right.$ a Abraham $\left.\left.\left.]\right]\right]\right]$ this place showed God to Abraham

'The Lord showed Abraham this place'

[Fontana (1993: 73)]

However, this structure fails to account for information-structural phenomena. In this sense, nowadays, there is general agreement in the fact that V2 Old Romance word order is a syntactic reflex associated to the expression of pragmatic information. Consistent with the cartographic model, that supplied a split CP domain to give an adequate explanation of the relationship between the syntactic representation of the sentence and its pragmatic and information structure, several scholars have regarded (2) as a case of focalization which can correspond to different types of foci-see Benincà (2004: 251): 
«The hypothesis that the Focus Field can host various kinds of Foci is relevant in particular for medieval Romance languages. This area appears to be more easily activated in those languages than in modern Italian, so that we find there not only contrastive Focus or wh elements, but also less 'marked' elements (an identificational, informational or 'unmarked' focus, an anaphoric operator, or even elements with the pragmatic characteristics of a topic 'put in relief')».

Consequently, if we extend Benincà's view to the example in (2), we get the following representation (see Batllori and Hernanz 2010):

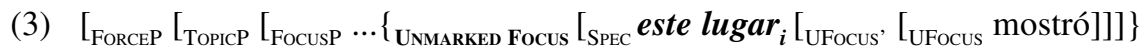
$\left[{ }_{\text {FINP }} \cdots .\left[_{V P}\right.\right.$ Dios $\left[{ }_{V},\left[_{V}, t_{V} t_{i}\right]\right.$ a Abraham $\left.\left.\left.\left.\left.]\right]\right]\right]\right]\right]$

The analysis in (3) expresses the fact that this pattern of focus fronting obtains by the leftward movement of unmarked non-focal (or mildly focal -see Gallego 2007) elements that would end up in a left peripheral functional category hierarchically lower than contrastive focus, and hence encode a rather different (non contrastive) value.

In sum, either on cartographic or on minimalist grounds, paying attention to information structure offers more explanatory adequacy and can allow us to work out better the syntactic configurations of older written texts.

The papers of this monograph analyze different syntactic changes and their interaction with information structure in the history of English as well as of Romance languages (Italo-Romance, Portuguese, Spanish and Catalan). The phenomena considered range from:

i) word order in the history of English: subject position changes from Old English to Middle English and Modern English compared to Present Day English (Theresa Biberauer and Ans van Kemenade); OV to VO changes in the evolution from Old English to Middle English, compared to Icelandic (Ann Taylor and Susan Pintzuk).

ii) word order in Old and Modern Romance: focalisation strategies in ItaloRomance (Old Italian, Old Neapolitan, Old Sardinian, Old Sicilian, etc.) in contrast with Modern Italo-Romance varieties (Silvio Cruschina); object scrambling in Old Portuguese compared to Contemporary European Portuguese (Ana Maria Martins); the interaction between information structure and word order in Old Spanish (Ioanna Sitaridou).

iii) genesis and syntax of D-linked elements: the discourse properties of expletiveexpressive ELLO and AÇÒ constructions in Romance (Anna Bartra); the left periphery of Old Catalan NP and the semantic evolution and categorial change of some Latin adjectives into Quantifiers (Bruno Camus and Manuel PérezSaldanya).

The author's conclusions may vary: Ann Taylor and Susan Pintzuk argue against relating the constraints of information status, on the one hand, with those of 
syntactic word order change from OV to VO, on the other. Theresa Biberauer and Ans von Kemenade are «in favour of seriously taking into consideration information structure in developing a fine-grained generatively oriented understanding of diachronic phenomena» and, particularly, in accounting for subject position changes in the history of English. Silvio Cruschina states that syntactic changes affecting word order in Old Italo-Romance, which have given rise to synchronic syntactic variation, are better understood in terms of their interaction and association with information structure. Ana Maria Martins pays attention to the information status of scrambled constituents in Old and Contemporary European Portuguese and concludes that object scrambling is a strategy to create appropriate information focus configurations. Ioanna Sitaridou acknowledges the relevance of the left peripheral discourse-sensitive Old Spanish field in viewing Old Spanish verb second orders as an epiphenomenon of the organisation of information structure. Anna Bartra offers a comprehensive explanation of D-linked contrastive elements checked in $\mathrm{T}$ or in C. Bruno Camus and Manuel Pérez-Saldanya examine the genesis of new structure in the left periphery of the Romance NP and the evolution of new quantificational values for Latin adjectives.

After this brief introduction, we include a summary of the contributions to this volume.

Theresa Biberauer and Ans van Kemenade offer a formal account of how the Information-Structure-sensitive Old English subject positions can be understood in the context of an OV system which was becoming VO. Agreeing in that the loss of $\mathrm{OV}$ orders and the shift to general VO had consequences for subject-related phenomena, they show that considering Information Structure (IS) factors brings about a more refined account of these consequences. They argue that, as objects ceased to be scrambled to little $v$ P over the Middle English period, Spec,TP came to host only subjects. Over the late Middle English period, the weakening of the IS-driven distinction between the higher subject position for discourse-old subjects, and Spec,TP for discourse-new subjects led to a reanalysis of the former two subject positions into one subject position (yet with robust evidence for a low, VP-internal, subject position in a wide range of unaccusative contexts, which barred a convergence on one single analysis for Spec,TP as the canonical subject location). According to them, the ambiguity with respect to the evidence for the nature of Spec,TP persists into Present-day English, which displays two subject positions diversified in line with their IS-properties.

Ann Taylor and Susan Pintzuk focus on the relation between syntactic change and information status on alternations in Old English and Early Middle English verbobject order (i.e., OV vs. VO). They present an analysis based on $1500 \mathrm{AuxV}$ and VAux clauses from seven Old English texts and three Middle English texts, and consider three independent variables that can influence the position of objects within the clause: text, information status and syntactic complexity. After building a quantitative model, they test it against the Old and Middle English data, and also against Icelandic historical data, and prove that the patterns predicted by their model show up 
clearly in both English and Icelandic. This confirms their main hypothesis according to which syntactic change and the constraints of information status are independent.

Silvio Cruschina sets out a comparison between Modern and Old Italo-Romance varieties to work out the mechanisms that rule the syntactic operations associated with the information structure of the sentence, and to identify their triggering factors. He focuses on the process of focalization and on verb movement. The fronting phenomena found in Old Italo-Romance varieties, which is still available in Modern Sardinian and Modern Sicilian, have been attributed to functional projections related to discourse properties and, ultimately, to information structure. A distinction between a higher, left peripheral FocP, and a lower, clause-internal FocP, provides the author with the basis for an account of both synchronic and diachronic variation that relies on the correlation between word order changes in diachrony, discourse-related features, and functional projections. He concludes that most of the 'so called V2' properties displayed by these languages are instead associated with discourse-related features and functional projections. Accordingly, the loss of verb raising is not due to the loss of a V2 syntax, but to a process of reanalysis that led to the deactivation of the higher focus projection and its attraction properties. Thus, he proves that changes in featural association, and in the activation of functional projections, have specific effects on the interaction between word order alternations and information structure.

Ana Maria Martins poses that object scrambling both in Old and Contemporary European Portuguese is a strategy to make the rightmost constituent escape the neutral sentence nuclear stress. She provides empirical evidence from European Portuguese to show that discourse/informational prominence on a particular constituent is compatible with broad information focus, which allows her to account for Old Portuguese data. She concludes that the informational import of the scrambling strategy is constant throughout the history of Portuguese. However, whereas both short scrambling (i.e. adjunction to VP) and middle scrambling (i.e. raising to multiple Spec,TP) were found in Old Portuguese, Contemporary European Portuguese only admits short scrambling. Hence, Old Portuguese scrambling could derive SOV sentences, while Contemporary European Portuguese scrambling only yields VO structures.

Ioanna Sitaridou investigates the interaction between information structure and word order in Old Spanish to shed light on (i) the evolution of word order from Old Spanish to Modern Spanish and (ii) the triggers, as well as the mechanisms, changing the interaction/mapping between information structure and syntax. She claims that verb second orders in Old Spanish are an epiphenomenon of the organisation of information structure, and states that in Old Spanish the discourse-sensitive field is exclusively the preverbal one, which can host both topics and foci, including verum foci and informational foci (the latter only available as the rightmost elements in Modern Spanish). Concerning object preposing, in particular, she shows that the object can either be linked to (i) a topic, (ii) an informational focus, (iii) a contrastive focus, or (iv) a verum focus reading. 
Anna Bartra revisits two types of apparently expletive neuter pronouns and demonstratives in Romance, which have been argued to belong to the Left Periphery of the sentence and to have an expressive value. She explores the relationship between expletive subjects and the Left Periphery in Null Subject languages and argues against the fact that grammaticalisation can explain the shift from expletive subject to expressive marker. Taking into consideration the common semantic properties of Catalan ell, Spanish ello, European Portuguese ele, etc., and the ones of neuter demonstratives (aço, eso, esto), she argues that these elements anchor a speech act, a predication to the external situation. Thus, they are Discourse-Linked contrastive elements related by an overt (or abstract) Central Coincidence $\mathrm{P}$ to the TP. Following Fortuny (2007), she puts forward that the features [D-Linked] and [contrast] can be checked in T or in C. As for their syntactic properties, she claims that these elements belong to a reduced C-T area.

Bruno Camus and Manuel Pérez-Saldanya study the growing structural complexity of the left margin of NP, and, as a result, the specialization of previous word classes for new positions conveying new values. They investigate the history of the development of new distributional patterns for some Latin adjectives and, in particular, the history of indefinite quantifiers in Catalan. The effect of this long term process is exemplified with the prototypical evolution from Old Catalan indefinites to their contemporary quantifier counterparts. Hence, the authors provide evidence to figure out the stages Romance adjectives have gone through in order to accommodate the distributional requirements of quantifiers and change into this new word class.

\section{References}

Research projects

Cheng, Lisa; Lubotsky, A. Sasha. Information structure in Welsh and its implications for diachronic syntactic change, Leiden University Centre for Linguistics, [http:// www.research.leiden.edu/research-profiles/language-diversity/research/welsh.html]

Donhauser, Karin; Petrova, Svetlana. The role of information structure in language change, Humboldt-Universität zu Berlin / Universität Potsdam, [http://www.sfb632. uni-potsdam.de/index_en.html]

\section{Bibliographical references}

Batllori, Montse; Hernanz, Maria-Lluïsa; Picallo, Carme; Roca, Francesc (eds.) (2005). Grammaticalization and Parametric Variation. Oxford: Oxford Univesity Press, pp. 1-18.

Batllori, Montserrat; Hernanz, Maria-Lluïsa (2010). «Sentential Focus and Polarity: Asymmetries between Spanish and Catalan». Poster: 12th Diachronic Generative Syntax Conference. July, 14th to 16th, 2010, Queen's College, University of Cambridge. [To appear in: Batllori, Montserrat; Hernanz, Maria-Lluïsa (In press). «Weak focus and polarity: asymmetries between Spanish and Catalan». In: Biberauer, 
Theresa; Walkden, George (eds.). Syntax over Time: Lexical, Morphological and Information-Structural Interactions. Oxford: Oxford University Press.]

Benincà, Paola (2004). «The Left Periphery of Medieval Romance». In: Studi Linguistici e Filologici Online. Rivista Telematica del Dipartimento di Linguistica dell'Università di Pisa. 243-297. [http://www.humnet.unipi.it/slifo/2004vol2/Beninca2004.pdf]

Breul, Carsten; Göbbel, Edward (eds.) (2010). Comparative and Contrastive Studies of Information Structure. Amsterdam: John Benjamins, Linguistics Today 165.

Cinque, Guglielmo; Rizzi, Luigi (2008). «The Cartography of Syntactic Structures». STiL - Studies in Linguistics. CISCL Working Papers 2: 42-58.

Ferraresi, Gisella; Lühr, Rosemarie (eds.) (2010). Diachronic Studies on Information Structure: Language Acquisition and Change. Berlin / New York: De Gruyter, Language, context, and cognition 10.

Fischer, Olga; Kemenade, Ans van; Koopman, Willem; Wurf, Wim van der (eds.). The Syntax of Early English. Cambridge: Cambridge University Press, pp. 1-35.

Fontana Fontana, Josep M. (1993). Phrase Structure and the Syntax of Clitics in the History of Spanish. Unpublished PhD Dissertation. University of Pennsylvania.

Gallego, Ángel J. (2007), «Defectivitat morfològica i variació sintàctica». Caplletra. 42: 219-249.

Kemenade, Ans van (2007). «Formal syntax and language change». Diachronica 24 (1): 155-169.

Rizzi, Luigi (1997). «The Fine Structure of the Left Periphery». In: Haegeman, L. (ed.). Elements of Grammar. Handbook in Generative Syntax. Dordrecht: Kluwer, pp. 281-337.

Roberts, Ian (2007). Diachronic Syntax. Oxford: Oxford University Press, chapters 3 and 4 .

Weestergaard, Marit (2010). «Cue-based Acquisition and Information Structure Drift». In: Ferraresi, Gisella; Lühr, Rosemarie (eds.) (2010), pp. 87-116. 